\title{
A descriptive and morphometric study of the fabellofibular, arcuate popliteal and popliteofibular ligaments*
}

\author{
Zeliha Kurtoğlu' ${ }^{1}$ Özlem Elvan ${ }^{1}$, Mustafa Aktekin ${ }^{2}$, Mehmet Çolak ${ }^{3}$ \\ ${ }^{1}$ Department of Anatomy, Mersin University Faculty of Medicine, Mersin, Turkey \\ ${ }^{2}$ Department of Anatomy, Acıbadem University Faculty of Medicine, Istanbul, Turkey \\ ${ }^{3}$ Department of Orthopaedics, Mersin University Faculty of Medicine, Mersin, Turkey
}

\begin{abstract}
Objectives: The anatomical relationship of the fibrous structures in the posterolateral corner of the knee is highly complex, with many different descriptions of these structures in the literature. Discrepancy in the definitions of FF, AL and PF are a problem for both clinicians and anatomists. This study aimed to examine these structures and describe their features to clarify our understanding of their morphology.

Methods: The posterolateral corner of the knee joint was bilaterally dissected in 10 male cadavers. Fibrous structures originating from the fibular head as a common mass were defined in relation to their attachment sites and positions according to the inferior lateral genicular vessels. The fabellofibular ligament (FF) was grouped into two categories, depending on the presence of a dense, fibrous tissue band. The arcuate popliteal ligament components were grouped into superficial (ALs) and deep (ALd) by their position relative to the inferior lateral genicular vessels. The popliteofibular ligament (PF) was identified as the fibrous bundle attached to the inferior border of popliteus tendon (PT). Dimensions of these structures were measured, and statistical analyses undertaken using paired and independent $t$-tests ( $p<0.05$ significant).

Results: FF had a dense fibrous band in 11 out of 20 knees. The fabella thickness was significantly higher in cases which FF had a dense fibrous band ( $p=0.04)$. ALs and PF were present in all knees. Absence of ALd was observed in 5 out of 20 knees.

Conclusion: Findings indicate the structural relationship between ALs and FF, variability in the morphology of the ligaments and a positive relationship between fabella thickness and FF morphology. Some structures were consistently present (AL, PF), while ALd was only present intermittently. We suggest descriptions of the posterolateral ligaments of knee that utilize attachment sites, relationships with the inferior lateral genicular vessels, and developmental relationships to the popliteus muscle to clarify terminology for these structures.
\end{abstract}

Keywords: arcuate popliteal ligament; fabellofibular ligament; popliteofibular ligament, posterolateral corner reconstruction Anatomy 2015;9(2):51-59 @2015 Turkish Society of Anatomy and Clinical Anatomy (TSACA)

\section{Introduction}

Injuries of posterolateral knee structures are uncommon, however they are functionally important as these structures play a major role in dynamic and static stabilization of the knee against varus and external rotation stresses. ${ }^{[1-6]}$ The posterolateral corner of the knee (PLC) has been defined as the "dark side" by orthopedists because of its complex structure. ${ }^{[1,4,7,8]}$ In addition, there are discrepancies between descriptions of the various ligamentous structures such as the fabellofibular (FF), arcuate popliteal (AL) and popliteofibular $(\mathrm{PF})$ ligaments in the literature..$^{[9-15]}$

One of the discrepancies is variety of descriptions of $\mathrm{AL}$ and FL. In some publications FF has been defined as "the strong vertical part of AL", while in others it has

*The study bad been presented in 15th National Congress of Anatomy, 2013, Samsun, Turkey 
been separately identified using different names such as "short lateral ligament", "short lateral genual ligament" or "short external ligament" ${ }^{[12,15,16]}$ Seebacher et al. ${ }^{[12]}$ first used the term "fabellofibular ligament", and described $\mathrm{FF}$ and $\mathrm{AL}$ as different structures. The frequency of FF has been reported in the literature as having a presence of $20-87 \% .^{[9,10,17,18]}$ Such a large range may be due to the variations in the $\mathrm{FF}$ and problems with its identification.

The fibrous tissue complex of PLC has been previously described as "arcuate ligament complex", "arcuate ligament" or "lateral capsular ligament complex", $[10,12,15,19]$ while only AL has been termed as "popliteal arcuate ligament", "arcuate ligament", "arcuate popliteal ligament", and "ligamentum popliteum arcuatum". $[8,10,13,14,17,20]$ The frequency of AL has been reported as between 13 and $80 \%$. $^{[8,17]}$

PF was first identified in 1894 as "the fibular attachment of the popliteal tendon". ${ }^{[10]}$ The first instance of the terminology "popliteofibular ligament" belongs to Oransky et al. ${ }^{[21]}$ who pointed out the role of PF in maintaining the functions of the knee, emphasizing that this structure should not be confused with AL. Maynard et al. ${ }^{[22]}$ supported the key role of PF among the posterolateral structures in terms of instability by biomechanical tests. Bolog and Hodler ${ }^{[17]}$ reported the frequency of PF in anatomical studies as $90-100 \%$, in in vitro MRI studies as $57-100 \%$ and in in vivo MRI studies as $8-53 \%$. There are studies that define PF as having only a single part, though there are those that define it as having two parts-anterior-posterior or superficial-deep..$^{[10,11,23,24]} \mathrm{On}$ the other hand, in some anatomical textbooks and atlases, there was no anatomical term or definition related with the $\mathrm{FF}$ and $\mathrm{PF},{ }^{[15,25-28]}$ while in others there are conflicting or unclear statements. ${ }^{[13,14]}$

It is essential to know the evolutionary and developmental anatomy of the knee in order to better understand the morphology of the regional structures, and to assist with developing precise and accurate terminology that correctly reflects the morphology and function of these ligaments. It has been known that both the fibula and tibia have joints with femur in early human embryonic development and then the fibular head (FH) shifts from femur to tibia. ${ }^{[1]}$ During the period that the $\mathrm{FH}$ articulates with the femur, the popliteus muscle tendon (PT) inserts to the FH. When the FH moves distally, PT maintains its original fibular insertion and acquires a femoral attachment as well. ${ }^{[1]}$ This means that PF is very likely the embryonic remnant of the popliteus muscle. While the fibula is moving away from the knee joint, the lateral part of the joint capsule is drawn inferiorly. ${ }^{[1,8,12]}$
Thus, AL is a continuation of the capsular ligamentous structures of the developing femorofibular joint.

Injuries of posterolateral corner of the knee are not very common but they are surgically important in terms of impairment of the posterolateral stabilization. ${ }^{[4,6]}$ These injuries were usually indicated by pathologic external tibial rotation and varus instability. ${ }^{[29]}$ Reconstruction of the arcuate ligament complex for the posterolateral rotatory instability has been reported for the first time by Hughston and Jacobson. ${ }^{[19]}$ Zhang et al. ${ }^{[30]}$ reported PF reconstruction as a good method for posterolateral knee instability treatment and pointed out the importance of the anatomical features of this structure. The lack of diagnosis and reconstruction of the ligament and related ligamentous structures are the leading reasons of anti-climax in reconstructive cruciate ligament surgery. ${ }^{[14]}$ Sun et al. could not identify PF by dualenergy CT, which is a new and valuable tool to qualitatively display the main ligaments of the knee. ${ }^{[31]}$ However, Bolog and Hodler ${ }^{[17]}$ stated that a partial tear of the PFL and injuries of the AL and FF may be indirectly recognized on $\mathrm{MR}$ images by the accompanying soft tissue edema and bleeding.

The aim of the present study was to examine the FF, $\mathrm{AL}$ and PF to clarify their morphology and physical relationship to each other to promote a deeper understanding of their potential function and relevance.

\section{Materials and Methods}

The posterolateral corner of both knees in 10 formalinfixed male cadavers (aged 45-93 years, average $70.40 \pm 17.52)$ were bilaterally dissected. Biceps femoris and plantaris muscles along with the lateral head of gastrocnemius were removed. FF, AL and PF were evaluated regarding their relationship with each other, morphometric features, and their position according to the inferior lateral genicular vessels (ILG).

Measurements for all structures were performed by the same researcher; all measurements were made with the knee in a prone, fully extended position. Linear measurements were undertaken using digital calipers (0.01 mm precision). Values are given as mean and standard deviations. Definitions of the ligaments were taken in accordance with the following descriptions (Figures $\mathbf{1 a}$ and $\mathbf{b})$ :

\section{Fabellofibular ligament}

The fascia originating from the lateral side of the knee was observed to attach the $\mathrm{FH}$ with variable thickness, fatty tissue content and fibrous tissue density (Figures $\mathbf{2} \mathbf{a}$ and 

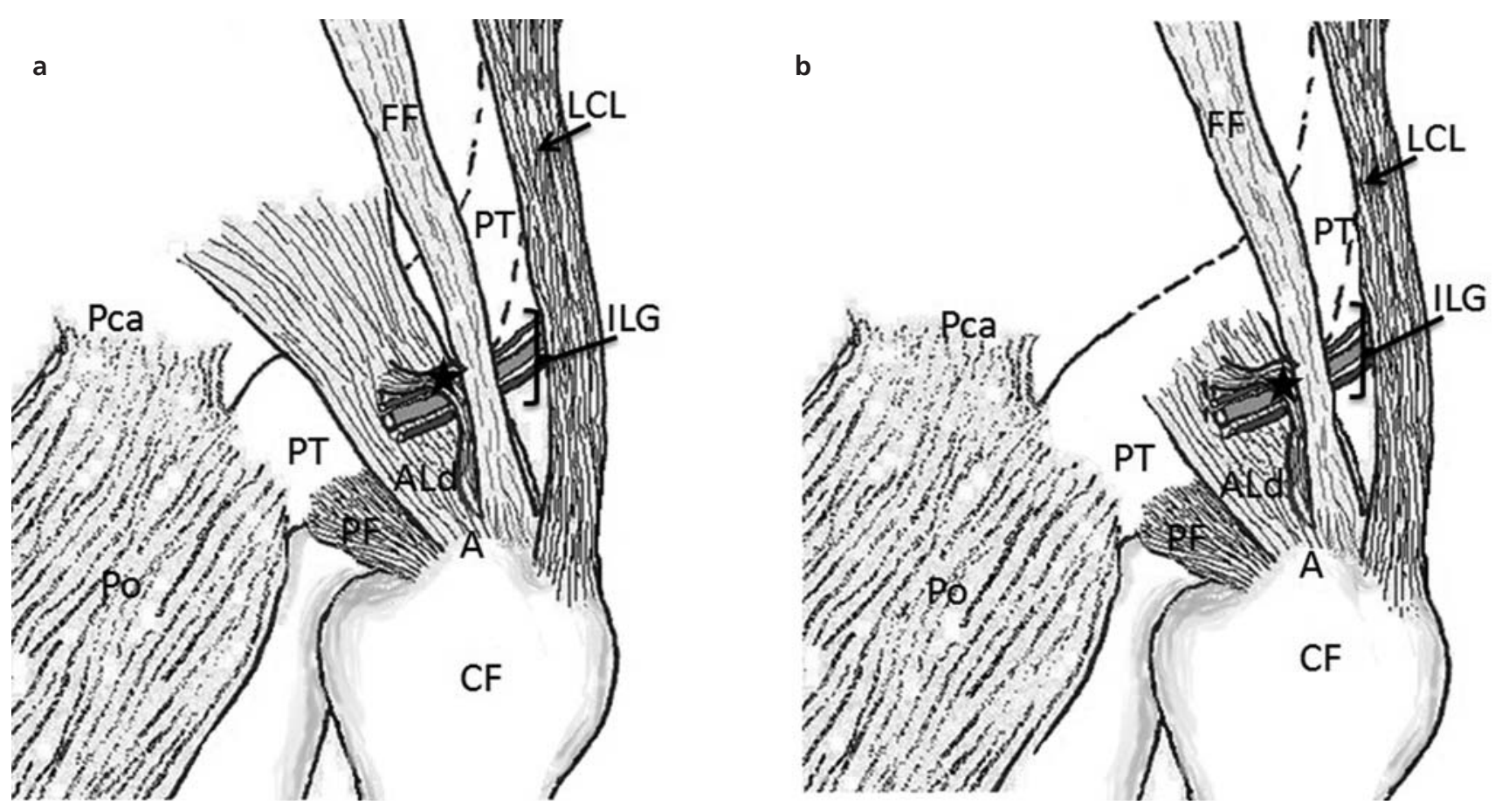

Figure 1. Schematic drawing showing the positions of the posterolateral corner ligaments. ALd is superficially crossing the PT to attach the capsule as a retinaculum (a), or may attach to the posterior aspect of PT through the capsule (b). A: apex of styloid process; ALd: deep part of arcuate popliteal ligament, black star: superficial part of arcuate popliteal ligament; CF: caput fibulae; FF: fabellofibular ligament; ILG: inferior lateral genicular artery and vein; LCL: lateral collateral ligament; Pca: capsular attachment of popliteus muscle; PF: popliteofibular ligament; Po: popliteus muscle; PT: popliteus muscle tendon; dotted line: intracapsular part of PT.

b). All fascial structures originating from the deeper side of the lateral head of the gastrocnemius muscle and passing towards the FH, regardless of their fatty or connective tissue content or thickness, were termed as FF.

Structures identified as FF were grouped into two depending on their fibrous tissue content: FF with an apparent fibrous band, and FF without a fibrous band.
The thickness of the tissue was measured superficial to ILG. In cases where the superficial part of AL and FF were fused and the dissection was impossible (Figure 3a), combined thickness was measured. In other cases where FF could be isolated from ALs by blunt dissection (Figure 3b), FF was measured alone. Due to the fact that $\mathrm{FF}$ appeared as a thickened part of the fascial formation,
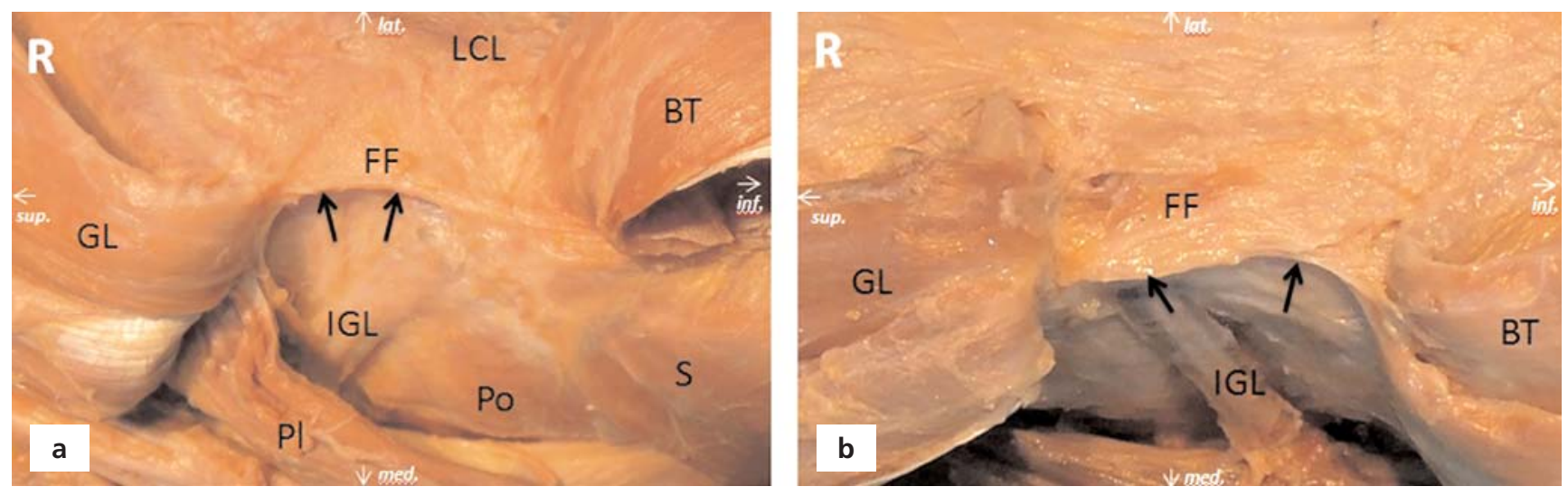

Figure 2. Right posterolateral views of the FF, with (a) and without (b) dense fibrous tissue. The lateral head of the gastrocnemius muscle was reflected superiorly and biceps femoris muscle was reflected inferiorly. BT: biceps femoris muscle tendon; FF: fabellofibular ligament, black arrows: free edge of FF; GL: gastrocnemius muscle, lateral head; ILG: inferior lateral genicular artery and vein; inf: inferior; lat: lateral; LCL: lateral collateral ligament; med: medial; PI: plantaris muscle; Po: popliteus muscle; R: right side; S: soleus muscle; sup: superior. 

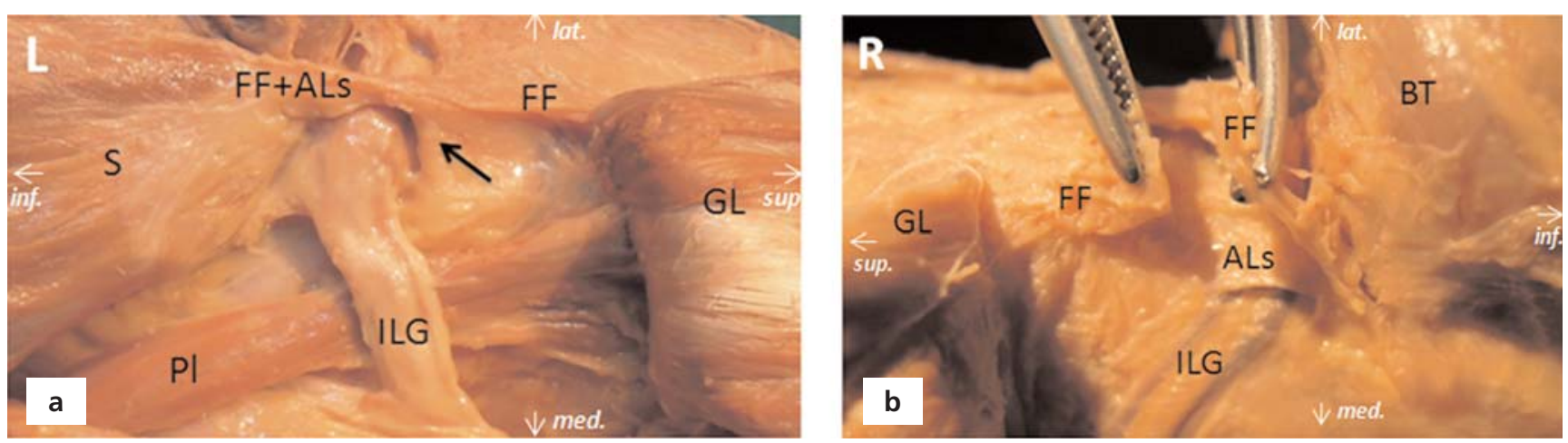

Figure 3. Posterior view of the relationship between FF and ALs in three knees. FF and ALs were fused superficial to ILG on left sides (a) ALS (arrow) is located deep to the FF, separated from FF, restraining the ILG superiorly and attached to the capsule. (b) FF was dissected from the deeply located ALs and cut on a left knee, ALs; was revealed as a band on the surface of ILG. ALs: superficial part of arcuate popliteal ligament; BT: biceps femoris muscle tendon; FF: fabellofibular ligament; GL: gastrocnemius muscle, lateral head; ILG: inferior lateral genicular artery and vein; inf: inferior; L: left side; lat: lateral; med: medial; PI: plantaris muscle; R: right side; S: soleus muscle; sup: superior.

the anterior and posterior borders of FF could not be clearly distinguished, so width of the structure was not measured.

The existence of fabella (osseous or cartilaginous) was taken into consideration in the evaluation of this ligament. The width, length and thickness of fabellae were measured.

\section{Arcuate popliteal ligament}

$\mathrm{AL}$ originates deep to $\mathrm{FF}$, passing around the styloid process of the fibula (SP), and inserting into the capsule. The capsular attachment site was anywhere on the posterior aspect of PT or superior to it (Figures $\mathbf{4 a - c}$ ). This criterion was set considering the information that $\mathrm{PF}$ is found attached to the PT during the embryonic developmental
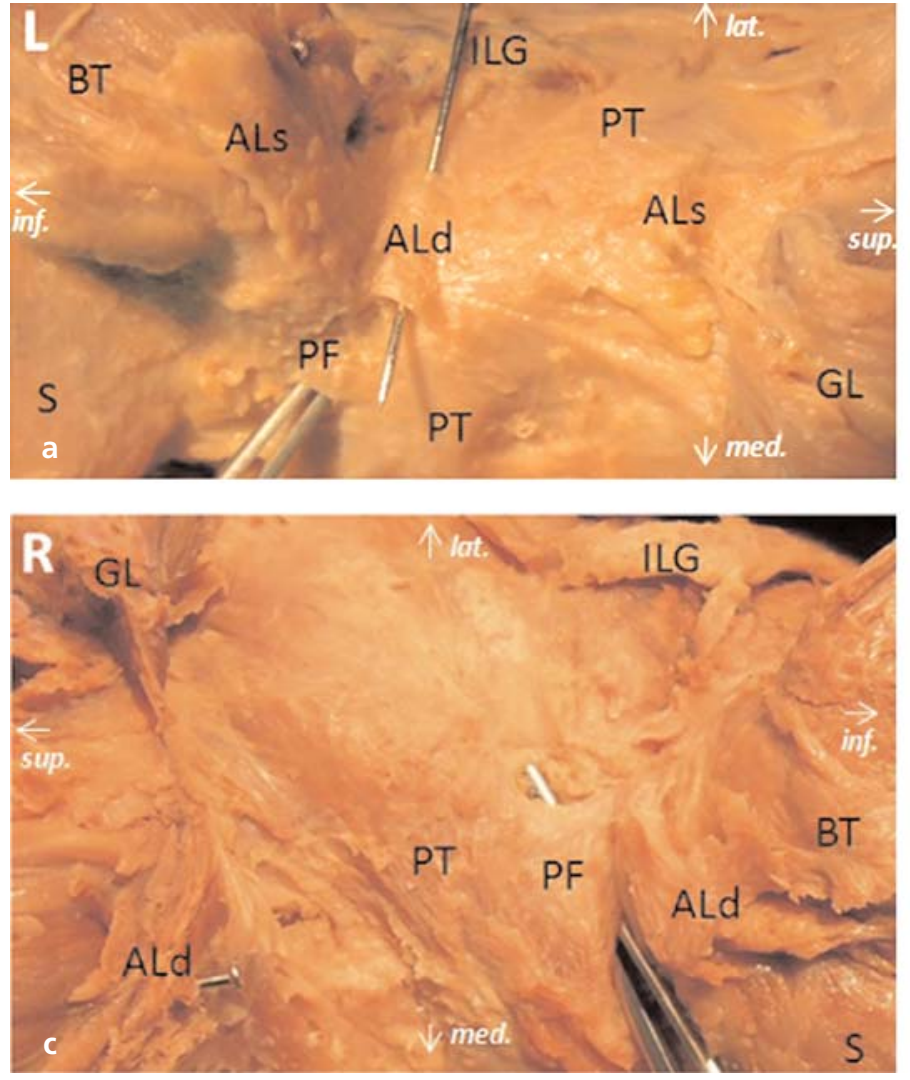

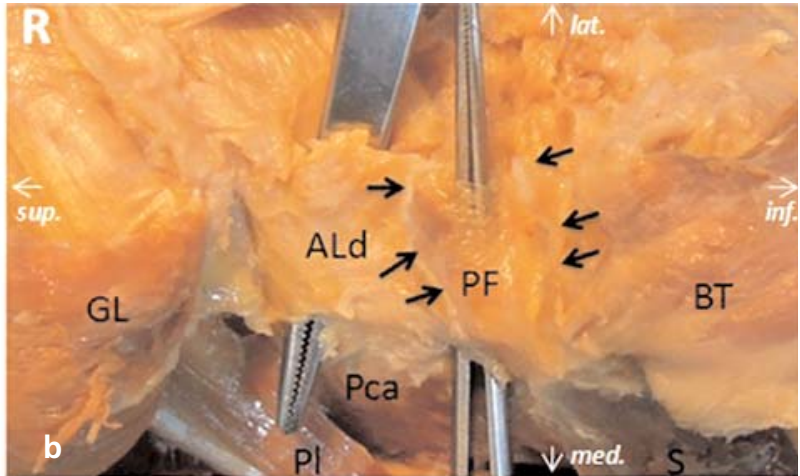

Figure 4. Positional relationship between ALd and PF in three different cases after removing FF, ALs and ILG. (a) ALd tightly attached to the posterior aspect of PT through the capsule; this case was more superficial and anterior with respect to PF. (b) ALd which coursed as a retinaculum toward the PT surface and the capsule superior to it. Forceps were located deep to the upper part of ALd. PF, which attached to the lower border of PT in a deeper plane was revealed by cutting the lower part of ALd. (c) A retinacular ALd which completely covered PF, was cut and drawn inferiorly to reveal the cone shaped PF. ALd: arcuate popliteal ligament, deep part; ALs: arcuate popliteal ligament, superficial part; arrows: cut edges of ALd which covered PF; BT: biceps femoris muscle tendon; GL: gastrocnemius muscle, lateral head; ILG: inferior lateral genicular artery and vein; inf: inferior; L: left side; lat: lateral; med: medial; Pca: capsular attachment of popliteus muscle; PF: popliteofibular ligament; PI: plantaris muscle; PT: popliteus muscle tendon; R: right side; S: soleus muscle; sup: superior. 
process and it reaches its terminal position by the completion of the fibula driftage, while AL is developing as a capsular ligament from the beginning of this process. ${ }^{[1,8]}$

Fibrous tissues which were compatible with the AL were evaluated according to their position to ILG as superficial (ALs) and deep (ALd) components. The width and thickness of each component were measured at the level of ILG.

\section{Popliteofibular ligament}

$\mathrm{PF}$ originates around $\mathrm{SP}$ and attaches to the lower edge of PT (Figures $4 \mathbf{a}-\mathbf{c}$ ). The width and thickness of PF were measured at its mid-point.

\section{Statistical methods}

Normal distribution of the variables was determined by Kolmogorov-Smirnov test. A paired t-test was used to evaluate the difference between the averages of the dependent variables (difference between the sides for each ligament and difference between the ALd and PF of the same case). Statistical difference between the types of FF (with and without fibrous band) with regard to dimensions of fabella was assessed by independent- test. A p-value of less than 0.05 was considered to be statistically significant.

\section{Results}

FF, ALs, ALd and PF appeared visually as structures of different densities. According to this qualitative assessment, PF seemed to be the most solid structure followed by ALd and ALs. FF was found to be voluminous but 'floppy' (i.e. not dense) in most cases.

$\mathrm{FF}$, ALs and ALd were conjoined fibrous tissues at their attachments on $\mathrm{FH}$ while they became separate at more superiorly. PF, on the other hand, seemed to be a part of the conjoined structure at FH in six cases where
Table 1

Presence of some morphological features of the FF, AL subtypes and PF on each case.

\begin{tabular}{|c|c|c|c|c|c|c|}
\hline Case & Side & $\begin{array}{c}\text { FF } \\
\text { fibrous } \\
\text { band (+/-) }\end{array}$ & $\begin{array}{c}\text { FF separable } \\
\text { form the } \\
\text { ALs (+/-) }\end{array}$ & $\begin{array}{l}\text { ALs } \\
(+/-)\end{array}$ & $\begin{array}{l}\text { ALd } \\
(+/-)\end{array}$ & $\begin{array}{c}\text { Partially } \\
\text { fused ALd-PF } \\
(+/-)\end{array}$ \\
\hline \multirow[t]{2}{*}{1} & $\mathrm{~L}$ & - & - & + & - & $\varnothing$ \\
\hline & $\mathrm{R}$ & + & - & + & + & - \\
\hline \multirow[t]{2}{*}{2} & $\mathrm{~L}$ & + & - & + & - & $\varnothing$ \\
\hline & $\mathrm{R}$ & + & - & + & - & $\varnothing$ \\
\hline \multirow[t]{2}{*}{3} & $\mathrm{~L}$ & + & - & + & + & - \\
\hline & $\mathrm{R}$ & + & + & + & + & - \\
\hline \multirow[t]{2}{*}{4} & $\mathrm{~L}$ & - & - & + & - & $\varnothing$ \\
\hline & $\mathrm{R}$ & - & - & + & + & - \\
\hline \multirow[t]{2}{*}{5} & $\mathrm{~L}$ & - & - & + & + & + \\
\hline & $\mathrm{R}$ & + & - & + & + & - \\
\hline \multirow[t]{2}{*}{6} & $\mathrm{~L}$ & + & - & + & + & - \\
\hline & $\mathrm{R}$ & + & - & + & + & - \\
\hline \multirow[t]{2}{*}{7} & $L$ & + & - & + & + & - \\
\hline & $\mathrm{R}$ & - & + & + & + & - \\
\hline \multirow[t]{2}{*}{8} & $\mathrm{~L}$ & - & + & + & + & + \\
\hline & $\mathrm{R}$ & - & - & + & + & - \\
\hline \multirow[t]{2}{*}{9} & $\mathrm{~L}$ & + & + & + & - & $\varnothing$ \\
\hline & $\mathrm{R}$ & - & + & + & + & + \\
\hline \multirow[t]{2}{*}{10} & $\mathrm{~L}$ & - & + & + & + & - \\
\hline & $\mathrm{R}$ & + & + & + & + & + \\
\hline Total & & 11 (5L/6R) & $7(3 \mathrm{~L} / 4 \mathrm{R}) \quad 2$ & 20 (10L/10R) & 15 (6L/9R) & $4(2 L / 2 R)$ \\
\hline
\end{tabular}

it was overlapped by ALd. In the other 14 cases PF had partially or totally separate attachment and was found on the posterior slope of SP.

Presence and bilaterality of the FF, AL types and PF are given in Table 1. No significant difference was found between the sides regarding the morphometric measurements of FF, ALs, ALd and PF by paired t test ( $p>0.05)$. Morphometric features of these ligaments are given in Table 2.

Table 2

Descriptive statistics regarding the morphometric measurements of FF, ALs, ALd and PF.

\begin{tabular}{|c|c|c|c|c|c|c|}
\hline & Measurement & n & $\operatorname{Min}(\mathrm{mm})$ & $\operatorname{Max}(\mathrm{mm})$ & Mean $(\mathrm{mm})$ & SD \\
\hline \multirow[t]{2}{*}{ Fabellofibular ligament (FF) } & thickness* & 7 & 0.20 & 1.30 & 0.94 & 0.37 \\
\hline & thickness $^{\dagger}$ & 13 & 0.80 & 2.90 & 1.62 & 0.63 \\
\hline \multirow[t]{2}{*}{ Arcuate popliteal ligament, superficial part (ALs) } & width & $19 \neq$ & 2.30 & 17.60 & 6.58 & 3.51 \\
\hline & thickness§ & 7 & 0.20 & 3.00 & 1.04 & 0.94 \\
\hline \multirow[t]{2}{*}{ Arcuate popliteal ligament, deep part (ALd) } & width & 15 & 3.10 & 17.60 & 8.73 & 4.15 \\
\hline & thickness & 15 & 0.10 & 1.30 & 0.82 & 0.35 \\
\hline \multirow[t]{3}{*}{ Popliteofibular ligament (PF) } & width & 20 & 5.00 & 16.50 & 9.80 & 2.92 \\
\hline & thickness & 20 & 0.40 & 2.40 & 1.29 & 0.51 \\
\hline & length & 20 & 5.70 & 12.30 & 8.22 & 1.75 \\
\hline
\end{tabular}

${ }^{*}$ Thickness for the sides those can be isolated from AL; ${ }^{\dagger}$ thickness for FF+ALs complex; ${ }^{\text {in }}$ one case, the anterior border of ALs could not be clarified because of its tight fusion with $\mathrm{FF}$, sthickness for the sides those can be isolated from FF; and the width of ALs excluded in this case. 
Fabellofibular ligament (Figures 2a, b, 3a-c)

$\mathrm{FF}$, as a band constructed of dense fibrous tissue, was found in 11 cases (Figures 2a and $\mathbf{b}$ ). FF with no distinct dense fibrous tissue was found in nine cases. It was observed that the fatty tissue, rather than the dense fibrous tissue, affected the ligament thickness in both groups.

In both groups, the inferior part of FF was supported by ALs. At this level, the relationship between ALs and FF was variable. In 13 cases, FF was tightly attached to ALs (Figure 3a) while in other seven cases they were easily separable in blunt dissection (Figure 3b). Cases in which $\mathrm{FF}$ and ALs were fused were defined as FF-ALs complex and its common thickness was measured (Table 2).

In 16 knees, fabella were observed. No significant difference was found between FF types regarding the width $(p=0.72)$ and length $(p=0.25)$ of fabella, while significant difference was detected between the groups regarding the fabella thickness: In cases with fibrous band, the fabella thickness was significantly higher than the other type $(\mathrm{p}=0.04)($ Table 3).

\section{Arcuate popliteal ligament}

ALs (Figures 3a, b, 4a, Table 1) were found in all sides. In 13 knees, it was fused with FF (Figures $\mathbf{2 a}$ and $\mathbf{b}$ ) while in seven others it was loosely attached to FF (Figure 3a). In all cases, ALs attached to the capsule by restraining the ILG superiorly (Figure 4a).

ALd (Figures 4a-c, Table 1) was absent in five knees (in all these knees, the whole AL was superficial to ILG). nine out of 15 cases with ALd, ALs was fused with FF while in other six it could be easily separated by blunt dissection In those five cases without ALd, ALs was fused with $\mathrm{FF}$ in four of them while it was free in one instance. In 11 sides, ALd attached to the capsule at the posterior surface of PT. In four knees, it was attached to the capsule more superior than the PT level.

\section{Popliteofibular ligament (Figures 4a-c)}

$\mathrm{PF}$ was identified in all knees. The morphometric features of FF, ALs, ALd and PF are given in Table 2.
ALd and PF were found partially fused in four sides (Table 1). Nevertheless, in these cases, ALd and PF could be separated from each other with blunt dissection. This partially conjoined set-up was defined as PFALd complex.

The positional relationship between ALd and PF was evaluated. In six knees ALd was completely overlapping PF. In four knees, ALd was partially covering the anterior portion of PF. In other 4 sides, PF and ALd were juxtapositioned. In one knee there was a distance between the posterior border of ALd and the anterior border of $\mathrm{PF}$. When ALd and PF were compared with paired t-test for their widths and thicknesses, no difference was found in their width $(\mathrm{p}=0.36)$ however, $\mathrm{PF}$ was found significantly thicker than ALd $(\mathrm{p}=0.04)$.

\section{Discussion}

The morphological characteristics of the posterolateral structures of the knee are of great importance in terms for surgery to help stabilize the posterolateral knee, however the discrepancy in the definitions of FF, AL and PF are a great problem for both clinicians and anatomists. This study assessed structures of the posterolateral knee to clarify their morphology to assist a clearer understanding of the anatomy of this region, with results indicating that the ligaments can be distinguished from each other using descriptions provided in this study (attachment sites and relationship to ILG), and considering the relationship of the ligaments with the popliteus muscle or capsule during the developmental process.

\section{Descriptive features of FF and ALs}

At the most superficial layer of PLC, all tissues originating from the lateral femoral epicondyle deep to the lateral head of the gastrocnemius muscle (fabellar region) and reaching to $\mathrm{FH}$ were defined as $\mathrm{FF}$. The ratio of "dense fibrous, loose connective and fatty tissues" within the same course and location was observed broadly varying. Such a great diversity could be a reason for difficulty in presenting a standard definition for this liga-

Table 3

The statistical difference between the types of FF regarding to the morphometric features of fabella by independent $t$ test.

\begin{tabular}{|c|c|c|c|c|c|c|c|c|c|c|}
\hline \multirow[b]{3}{*}{ Type of FF } & \multirow[b]{3}{*}{$\mathbf{n}$} & \multicolumn{9}{|c|}{ Fabella } \\
\hline & & \multicolumn{3}{|c|}{ Width } & \multicolumn{3}{|c|}{ Length } & \multicolumn{3}{|c|}{ Thickness } \\
\hline & & Mean & SD & $\mathbf{p}$ & Mean & SD & p & Mean & SD & $p$ \\
\hline Fibrous band + & 9 & 12.04 & 3.20 & \multirow{2}{*}{0.724} & 13.40 & 3.78 & \multirow{2}{*}{0.248} & 4.06 & 1.04 & \multirow{2}{*}{0.044} \\
\hline No fibrous band & 7 & 12.57 & 2.45 & & 11.60 & 1.19 & & 2.76 & 1.31 & \\
\hline
\end{tabular}


ment, and the described frequency of FF ranging between $20-87 \% .^{[9,10,17,18]}$ We detected the FF with an actual ligament appearance in 11 sides in our series. Any fibrous structure coming from the $\mathrm{FH}$ and attached to the capsule, without reaching to femoral epicondyle, was discriminated from the FF and indicated as AL.

In the present study, a fibrous structure diverging from FF at the upper border of ILG and tightly attached to the capsule by confining ILG was defined for the first time. This structure was evaluated as whether it was a part of the FF or not: in all sides, it was attached to the capsule far away from the region of the fabella. In seven sides, it was possible to isolate this structure as a separate band by blunt dissection, however in the remaining knees it was fused with FF. Due to its attachment to the capsule, which was removed from the fabellar region, this structure was evaluated as the superficial part of AL (ALs) rather than FF. We believe that the dissectible form of this structure seems to be defined by Ishigooka et al. ${ }^{[10]}$ as total AL (not a superficial component of AL), while the fused form of ALs with FF has not previously been mentioned.

Seebacher et al. ${ }^{[12]}$ evaluated $\mathrm{FF}$ and $\mathrm{AL}$ regarding to support of posterolateral corner of the knee. They reported the incidence of the cases in which only $\mathrm{AL}$ supported the capsule as $13 \%$, while those only FF supported the knee was $20 \%$ and both structures supported the capsule as $67 \% .{ }^{[12]}$ However, in their studies PF has not been mentioned; the structure that we defined here as PF was regarded as AL. Thus, the FF Seebacher et al. ${ }^{[12]}$ refer to could correspond to both of $\mathrm{FF}$ and $\mathrm{AL}$ in this study. In the present study, FF was qualitatively assessed as 'thick' however it seemed to be mostly comprised of fatty and loose connective tissue content and gave the impression that it would provide minimal assistance for the purpose of joint stabilization.

\section{FF and presence of fabella}

The relationship of the fabella and FF is also a controversial issue in the literature. Some authors have suggested that FF is seen only in the presence of the fabella, ${ }^{[12,29]}$ while some others stated that it can be found even in the absence of fabella. ${ }^{[17,32]}$ Zeng et al ${ }^{[9]}$ proposed that the presence of fabella did not correlate with the size or frequency of FF, whereas Seebacher et al ${ }^{[12]}$ noted that when the fabella was large, AL was absent and FF was strong. In addition, Seebacher suggested that if the fabella or its cartilaginous remnant was absent, then FF was absent and only AL was found. Minowa et al. ${ }^{[8]}$ reported that a bony fabella was often accompanied by a thick FF, whereas a cartilaginous fabella was never asso- ciated with a thick FF. In our study, it was interesting that the FF cases with fibrous band were accompanied by the thicker fabella. This finding supports the previous observations of Seebacher et al..$^{[1]]}$ and Minowa et al. ${ }^{[8]}$

\section{As a landmark ILG}

In discriminating PLC structures, ILG has been used as a landmark in different ways: Seebacher et al. ${ }^{[12]}$ stated that FF and AL always separated from each other by ILG and defined AL as "the ligament located deep to ILG". According to Oransky et al. ${ }^{[21]} \mathrm{AL}$ is found "superficial" to the ILG in the embryonic period, while Ishigooka et al. ${ }^{[10]}$ asserted that ILG may pass deep or superficial to or through AL. Minowa et al. ${ }^{[8]}$ found the ILG deep to AL in fetuses while ILG was localized superficial to the "arcuate ligament complex" in adults. They suggested the reason for this alteration as the secondary change of the basic laminar configuration of connective tissue complex during growth and aging. ${ }^{[8]}$

In the present study, in regards to the definition of the ALs and ALd, we considered their positions according to ILG. The remarkable finding was that ALs was present in all cases, and always attached to the capsule just like a boundary bundle for ILG. Such a fibrous tissue structure is mistakenly mentioned by some authors as the whole of $\mathrm{AL},{ }^{[8]}$ while by the others as $\mathrm{FF}^{[12]}$ as a result of absence of any clear definition for FF, AL and PF.

\section{Discrimination of ALd and PF}

The frequency of AL has been reported as between 13 and $80 \%$, which is perhaps an indication of the difficulty of distinguishing this structure from $\mathrm{PF} ;{ }^{[8,17]}$ the term $\mathrm{PF}$ was not used in the study of Seebacher et al ${ }^{[12]}$ Both $\mathrm{AL}$ and PF have been mentioned in the recent studies. ${ }^{[8,10,20,23,32]}$ Kim et al. ${ }^{[32]}$ stated that AL could be composed of single, double or multiple layers, and it was sometimes difficult to differentiate it from the PF. Ishigooka et al. ${ }^{[10]}$ indicated that PF tightly attaches to $\mathrm{PT}$ whereas AL is slender and courses superficial to PF and PT, and to the posterior articular capsule, without any tight attachment to PT. Feipel et al. ${ }^{[20]}$ gave the incidence of the cases that AL attached to PT as $90 \%$.

In the present study, by taking into account that the $\mathrm{AL}$ is a remnant ligament of the primitive fibula-femoral joint, ${ }^{[1]}$ it was identified as a fibrous tissue bundle that attached not directly to PT, but to the joint capsule on the posterior surface of $\mathrm{PT}$ or to a more superior point of the capsule. Regarding the PT's early developmental fibular insertion, ${ }^{[1]}$ the fibrous tissues attached directly to the inferior aspect of PT and were subsequently defined 
as PF. Similarly, Minova et al ${ }^{[8]}$ claimed the relation of $\mathrm{AL}$ and PF with PT as follows: "AL forms a retinaculum for PT but PF is the branch of PT". Although their statements contain both ALs and ALd, each of these parts was not specified by Minova et al. ${ }^{[8]}$

Similar to this study, Ishigooka et al. ${ }^{[10]}$ identified PF in all cases. While there are studies that reported PF absence in various frequencies between 2 and $62.5 \%{ }^{[4,18,20]}$ Ishigooka et al. ${ }^{[10]}$ claimed that studies which reported $\mathrm{PF}$ absence might misinterpret the position of the superficial part of PF due to its close location to AL, as well as its similar course and position. We suggest that this possible misinterpretation could also be related with an explanation of PF existing with two parts. Some authors have suggested the PF exists in two parts as anterior-posterior or superficial-deep. ${ }^{[10,11,23,24]}$ while others state it exists as a single structure. ${ }^{[8]}$ Ishigooka et al. ${ }^{[10]}$ isolated the PF in two layers in $30.8 \%$ of cases. We believe that the previously mentioned anterior (or superficial) part of PF corresponds to ALd in our classification.

Kim et al. ${ }^{[23]}$ stated that FF and AL are usually too small to have a significant role in knee joint posterior stability, thus it has been suggested that the surgical reconstruction procedure should be planned by considering PF. LaPrade et al. ${ }^{[1]}$ stated that the posterior part of PF was always larger than the anterior part (ALd of our study). In our series, $\mathrm{PF}$ was thicker than ALd $(\mathrm{p}=0.04)$ while there was no significant difference between the widths of PF and ALd $(p=0.36)$. Our measurements for length and width of $P F$ is compatible with literature. ${ }^{[1,22]}$ The thickness of both parts $(2.1 \mathrm{~mm})$ measured by Ishigooka et al ${ }^{[10]}$ is similar to the sum $(2.11 \mathrm{~mm})$ of PF and ALd measurements in our study (Table 2). We suggest that ALd should be considered separately from the PF with its attachment sites and morphometrical features in planning the surgical procedure and biomechanical studies as well.

The relationship between PF and ALd is also inconsistently reported between studies. Minova et al. ${ }^{[8]}$ stated that $\mathrm{PF}$ was located at the same level with AL. In our study, PF was always found deeper than ALd, with ALd overlapping PF totally in six cases, partially in four, and in the rest, ALd was beginning where the PF ends. Ishigooka et al. ${ }^{[10]}$ classified their orientation in three types: deep layer was posterior to the superficial in $9 \%$ of the cases, the layers were overlapping in $12.8 \%$ and deep layer was in front in $9 \%$. Unlike Ishigooka et al., ${ }^{[10]}$ in none of the knees in our series was PF found anterior to AL.

\section{Limitations of the study}

Due to the limited number of female cadavers and restricted (elderly) age group of male cadavers, variations depending on gender and age differences could not be evaluated. The small number of the subjects limited the statistical analyses that can be performed with subgroups (i.e. fibrous-non fibrous FF, fused-free forms of ALs, cases without ALd etc.). Data from larger series will enable analysis on such subgroups. The histological effects of formalin fixation have been stated as tissue shrinkage and destroyed elastic fibers, ${ }^{[3,34]}$ and it is possible embalming may have affected the tissues assessed in this study.

\section{Conclusion}

This study is the first to describe the relationship between ALs and FF, with findings also highlighting the variability in the morphology of FF and a relationship between fabella dimensions and FF morphology. We propose that ILG are used as a reference structure for identifying the superficial and deep parts of AL. PF has been identified as the developmental remnant of the fibular attachment of popliteus muscle. On the other hand, it was thought reasonable to consider ALd as a continuation of capsular ligamentous structures of the primitive femorofibular joint rather than a part of $\mathrm{PF}$, as it is attached to the capsule instead of PT. We suggest that the descriptions and definitions utilized in this study may potentially assist in providing common terms that could be useful for both anatomy and surgery, and that these definitions could also be included in revised anatomical texts. Finally, morphological and morphometric data from this study will be helpful in the planning of surgical reconstruction of PF and in related biomechanical studies.

\section{References}

1. Covey DC. Injuries of the posterolateral corner of the knee. J Bone Joint Surg Am 2001;83-A:106-18.

2. Espregueira-Mendes JD, da Silva MV. Anatomy of the lateral collateral ligament:a cadaver and histological study. Knee Surg Sports Traumatol Arthrosc 2006;14:221-8.

3. Brinkman JM, Schwering PJA, Blankevoort L, Koolos JG, Luites $\mathrm{J}, \mathrm{Wymenga} \mathrm{AB}$. The insertion geometry of the posterolateral corner of the knee. J Bone Joint Surg Br 2005;87-B:1364-8.

4. Camarda L, Condello V, Madonna V, Cortese F. Results of isolated posterolateral corner reconstruction. J Orthopaed Traumatol 2010;11:73-79.

5. Jung GH, Kim JD, Kim H. Location and classification of popliteus tendon's origin:cadaveric study. Arch Orthop Trauma Surg 2010;130:1027-32.

6. Kim JG, Lee YS, Ha JK, Jun SS, Jin YC. Influence of knee flexion and femoral cross-pin insertion angle on posterolateral structures of the knee and lateral fixation lengths during ACL reconstruction. Surg Radiol Anat 2012;34:421-5.

7. Wadia FD, Pimple M, Gajjar SM, Narvekar AD. An anatomic study of the popliteofibular ligament. International Orthopaedics 2003;27:172-4. 
8. Minowa T, Murakami G, Suzuki D, Uchiyama E, Kura H, Yamashita T. Topographical histology of the posterolateral corner of the knee, with special reference to laminar configurations around the popliteus tendon: a study of elderly Japanese and latestage fetuses. J Orthop Sci 2005;10:48-55.

9. Zeng SX, Dong XL, Dang RS, Wu GS, Wang JF, Wang D, Huang HL, Guo XD. Anatomic study of fabella and its surrounding structures in a Chinese population. Surg Radiol Anat 2012;34:65-71.

10. Ishigooka H, Sugihara T, Shimizu K, Aoki H, Hirata K. Anatomical study of the popliteofibular ligament and surrounding structures. J Orthop Sci 2004;9:51-8.

11. LaPrade RF, Ly TV, Wentorf FA, Engebretsen L. The posterolateral attachments of the knee: a qualitative and quantitative morphologic analysis of the fibular collateral ligament, popliteus tendon, popliteofibular ligament, and lateral gastrocnemius tendon. Am J Sports Med 2003;3:854-60.

12. Seebacher JR, Inglis AE, Marshall JL, Warren RF. The structure of the posterolateral aspect of the knee. J Bone Joint Surg Am 1982;64:536-41.

13. Standring S, editor. Gray's anatomy: the anatomical basis of clinical practice. 39th ed. Edinburgh (Scotland): Elsevier Churchill Livingstone; 2005. p. 1478-80.

14. Standring S, editor. Gray's anatomy: the anatomical basis of clinical practice. 40th ed. London: Elsevier Churchill Livingstone; 2005. p. 1400-8.

15. Williams PL, Bannister LH, Collins P, Dyson M, Ferguson MWJ, editors. Gray's anatomy: the anatomical basis of clinical practice. 39th ed. Edinburgh (Scotland): Elsevier Churchill Livingstone; 1995. p. 702.

16. LaPrade RF. Posterolateral knee injuries: anatomy, evaluation, and treatment. New York: Thieme Medical Publishers; 2006. p. 33.

17. Bolog N, Hodler J. MR imaging of the posterolateral corner of the knee. Skeletal Radiol 2007;36:715-28.

18. Sudasna S, Harnsiriwattanagit K. The ligamentous structures of the posterolateral aspect of the knee. Bull Hosp Jt Dis Orthop Inst 1990;50:35-40.

19. Hughston JC, Jacobson KE. Chronic posterolateral rotatory instability of the knee. J Bone Joint Surg Am 1985;67:351-9.

20. Feipel V, Simonnet ML, Rooze M. The proximal attachments of the popliteus muscle: a quantitative study and clinical significance. Surg Radiol Anat 2003;25:58-63.
21. Oransky M, Canero G, Maiotti M. Embryonic development of the posterolateral structures of the knee. Anat Rec 1989;225:347-54.

22. Maynard MJ, Deng X, Wickiewicz TL, Warren RF. The popliteofibular ligament: rediscovery of a key element in posterolateral stability. Am J Sports Med 1996; 24:311-6.

23. Kim JG, Ha JG, Lee YS. Posterolateral corner anatomy and its anatomical reconstruction with single fibula and double femoral sling method: anatomical study and surgical technique. Arch Orthop Trauma Surg 2009;129:381-5.

24. Stäubli HU, Birrer S. The popliteus tendon and its fascicles at the popliteal hiatus: gross anatomy and functional arthroscopic evaluation and without anterior cruciate ligament deficiency. J Arthroscopy 1990;6:209-20.

25. Gilroy AM, MacPherson BR, Ross LM, Schünke M, Schulte E, Schumacher U. Atlas of anatomy: 2nd ed. New York: Thieme Medical Publishers; 2012. p. 409.

26. Moore KL, Dalley AF. Clinically oriented anatomy. 4th ed Baltimore: Lippincott Williams and Wilkins; 1999. p. 586.

27. Rohen JW, Yokochi C, Lütjen-Dtecoll E. Anatomie des Menschen. Fotografischer Atlas der systematischen und topografischen Anatomie. Stuttgart: Schattauer; 2006. p. 446.

28. Federative Committee of Anatomical Terminology (FCAT). Terminologia anatomica. Stuttgart: Thieme; 1998.

29. Davies H, Unwin A, Aichroth P. The posterolateral corner of the knee. Anatomy, biomechanics and management of injuries. Injury 2004;35:68-75.

30. Zhang H, Feng H, Hong L, Wang XS, Zhang J. Popliteofibular ligament reconstruction for posterolateral external rotation instability of the knee. Knee Surg Sports Traumatol Arthrosc 2009;17:1070-7.

31. Sun C, Miao F, Wang X, Wang T, Ma R, Wang D, Liu C. An initial qualitative study of dual-energy CT in the knee Ligaments. Surg Radiol Anat 2008;30:443-7.

32. Kim YC, Chung IH, Yoo WK, Suh JS, Kim SJ, Park CI. Anatomy and magnetic resonance imaging of the posterolateral structures of the knee. Clin Anat 1997;10:397-404.

33. Fox CH, Johnson FB, Whiting J, Roller PP. Formaldehyde fixation. J Histochem Cytochem 1985;33:845-53.

34. Abe M, Takahashi M, Horiuchi K, Nagano A. The changes in crosslink contents in tissuesafter formalin fixation. Analytical Biochemistry 2003;318:118-23.

Correspondence to: Zeliha Kurtoğlu, MD

Department of Anatomy, Faculty of Medicine,

Mersin University, Mersin, Turkey

Phone: +903243410684/1089

e-mail: zkurtoglu@yahoo.com

Conflict of interest statement: No conflicts declared.

This is an open access article distributed under the terms of the Creative Commons Attribution-NonCommercial-NoDerivs 3.0 Unported (CC BY-NCND3.0) Licence (http://creativecommons.org/licenses/by-nc-nd/3.0/) which permits unrestricted noncommercial use, distribution, and reproduction in any medium, provided the original work is properly cited. Please cite this article as: Kurtoğlu Z, Elvan Ö, Aktekin M, Çolak M. A descriptive and morphometric study of the fabellofibular, arcuate popliteal and popliteofibular ligaments. Anatomy 2015;9(2):51-59. 